\title{
Predictive value of different radiographic parameters evaluating the proximal femoral geometry for hip fracture in the elderly: what is the role of the true moment arm?
}

\author{
Yunus Imren ${ }^{1}$, Hakan Sofu², Suleyman Semih Dedeoglu ${ }^{1}$, Engin Eren Desteli ${ }^{3}$, Haluk Cabuk ${ }^{1}$, \\ Mustafa Caglar Kir ${ }^{1}$
}

\begin{abstract}
${ }^{1}$ Department of Orthopaedics and Traumatology, Okmeydani Training and Research Hospital, Istanbul, Turkey

Department of Orthopaedics and Traumatology, Erzincan University, Erzincan, Turkey ${ }^{3}$ Department of Orthopaedics and Traumatology, Uskudar State Hospital, Istanbul, Turkey
\end{abstract}

Submitted: 24 May 2016

Accepted: 19 June 2016

Arch Med Sci Civil Dis 2016; 1: e58-e62

DOI: 10.5114/amscd.2016.60904

Copyright @ 2016 Termedia \& Banach

\section{Abstract}

Introduction: The purpose of the present study was to evaluate the value of radiographic measurements of the proximal femur as predictive factors for hip fracture in the elderly population independent of bone mineral density. Material and methods: The study included 142 consecutive patients operated on for a hip fracture (group 1) and 86 healthy individuals without a hip fracture (group 2). The geometry of the contralateral nonfractured proximal femur in patients from group 1 was evaluated in comparison with healthy individuals from group 2. Anteroposterior pelvic roentgenograms were assessed to measure the geometric parameters of the proximal femur including femoral neck width, $\mathrm{Q}$ angle, medial cortical thickness (MCT), lateral cortical thickness (LCT), and true moment arm (TMA) for all hips. Lunar dual-energy X-ray absorptiometry (DXA) was used for bone mineral density measurements in both the fracture and control groups. Multivariate regression analysis was performed to determine the main predictive factors. A receiver operating characteristic curve was constructed for TMA to test the various cut-off points in predicting hip fracture.

Results: Regarding geometric measurement parameters, group 1 had significantly lower MCT and LCT values. The mean femoral neck width (FNW) and $\mathrm{Q}$ angle were significantly higher in group 1. Furthermore, TMA was also found to be significantly greater in patients with hip fracture compared to controls, $85 \pm 14 \mathrm{~mm}$ and $66 \pm 12 \mathrm{~mm}$, respectively $(p<0.001)$. The mean TMA was also significantly greater in group 1 for both age groups $(\leq 65$ or $>65$ years $)(p<0.001)$.

Conclusions: True moment arm may provide the most valuable radiographic information as a predictor for hip fracture in the elderly.

Key words: bone density, aged, predictive value of tests, hip fractures/ pathology.

\section{Introduction}

As the elderly population has been growing worldwide in recent decades, hip fracture has become a major public health problem due to increases in the number of adults with osteoporosis. Hip fractures in this

\author{
Corresponding author: \\ Yunus Imren \\ Department of Orthopaedics \\ and Traumatology \\ Okmeydani Training \\ and Research Hospital \\ Darulaceze Caddesı No. 25 \\ Sıslı, 34382 Istanbul, Turkey \\ Phone: +90 5423661038 \\ E-mail: yunusimren@gmail. \\ com
}


age group are among the most common acute pathologies in the daily clinical practice of orthopedic traumatology [1]. It has been estimated that the incidence of hip fracture will rise to more than 6 million by the year 2050 [2, 3]. Approximately $25 \%$ of the patients have been reported to die from complications within the first year after the fracture, whereas another $25 \%$ are at risk of losing independence [4]. Therefore, identifying individuals who are at high risk of hip fracture could prevent or delay fracture and its devastating consequences [5].

Although low bone mineral density (BMD) has been proposed as the major predictive factor in establishment of a risk level in the older population, a large overlap in the BMD values of fracture and non-fracture patients has led physicians to focus on investigating additional methods and parameters such as the proximal femoral geometry [6-8]. Hip axis length (HAL), femoral neck axis length (FNAL), femoral neck shaft angle (Q angle), femoral neck width (FNW), medial and lateral cortical thicknesses (MCT and LCT), and true moment arm (TMA) are the major radiographic parameters which have been tested as potential predictors of hip fracture [7, 9-12]. Some authors have suggested a combined assessment of proximal femur geometry and BMD values [10]. However, no consensus has been established yet on the validity of structural variations of the proximal femur which may potentially improve the clinical predictability of hip fractures in the elderly.

The purpose of the present study was to evaluate the value of radiographic measurements of the proximal femur including FNW, Q angle, MCT, LCT, and TMA as predictive factors for hip fracture in the elderly population and the ability to identify fracture-prone individuals, independently of BMD.

\section{Material and methods}

After having approval from the local ethical research committee (ref. 15144-468), the present study comparatively evaluated the data of patients who underwent surgical treatment for a hip fracture with the data of healthy individuals. Informed consent was obtained from all individual participants included in the study. Polytrauma patients, bilateral hip fractures, fractures associated with a primary or secondary tumor of the bone, patients who had a past medical history of hip surgery, those with primary or secondary musculoskeletal deformities of the lower extremity, metabolic diseases of bone except osteoporosis, and patients with inappropriate or incomplete radiographic records were excluded. The study population consisted of 142 consecutive patients operated on for a hip fracture (group I) and 86 healthy individuals without a hip fracture (group II). The mean age of the patients in group I was $78.3 \pm 9.2$ years at the time of hip fracture and $76.3 \pm 9.4$ years in group II. The mean body mass index (BMI) was $25.5 \pm 2.1 \mathrm{~kg} / \mathrm{m}^{2}$ in hip fracture patients and $25.4 \pm 3.5 \mathrm{~kg} / \mathrm{m}^{2}$ in the control group. Group I included 92 (64.7\%) females and 50 (35.2\%) males, whereas group II included 62 (72\%) females and 24 (28\%) males. In group I, the preoperative diagnosis was intracapsular femoral neck fracture in 64 (45\%) patients, and intertrochanteric or subtrochanteric fracture in 78 (55\%).

The geometry of the contralateral nonfractured proximal femur in patients from group I was comparatively evaluated with the geometry of the proximal femur in healthy individuals from group 2. The right and left hips (172 hips of the 86 subjects) were examined in the control group, while the nonfractured hips including 59 right and 83 left sides were examined in the fracture group. The standardized anteroposterior (AP) pelvic roentgenograms were assessed. The standard AP pelvic image was taken while the patient was lying in a supine position with the tube perpendicular to the table and the central beam was between the upper border of the symphysis pubis and anterior superior iliac spines. The optimal AP image was accepted as the coccyx points toward the symphysis pubis with a distance of 1 to $2 \mathrm{~cm}$ to it. The measured geometric parameters of the proximal femur included femoral neck width, Q angle, medial and lateral cortical thickness, and the true moment arm for all hips (Figure 1). The formula described by Ulusoy et al. [9] was applied to calculate TMA. The formula used to calculate TMA was as follows; $T M A=\operatorname{sine}(Q-90) \times$ femur

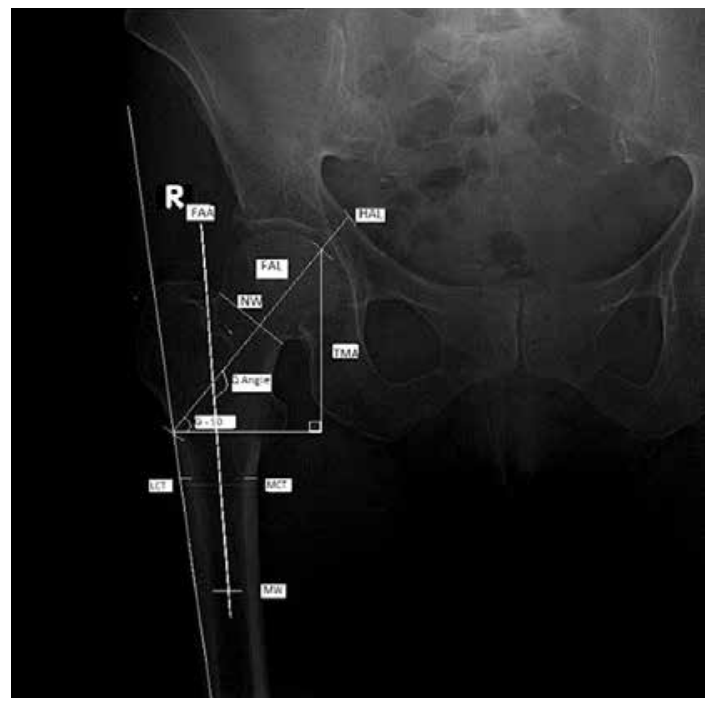

Figure 1. Measurement of geometric parameters of the proximal femur on X-ray

HAL - hip axis length, FAL - femur axis length, TMA - true moment arm, NW - neck width, FAA - femur anatomic axis, LCT - lateral cortical thickness, MCT - medial cortical thickness, $M G$ - medullary width. 
axis length (FAL). All of the radiographic measurements were performed by two of the authors. Correlation coefficients for the measurements were $0.96,0.91,0.99,0.99$ and 0.90 for FNW, Q angle, MCT, LCT, and TMA, respectively.

Lunar DXA was used for BMD measurements for all hips in both the fracture and control groups. The measurements were performed on the nonfractured side of the patients in group I and on both hips of the subjects in group II. BMD measurements were obtained as femoral neck, trochanteric region, and total BMD values.

\section{Statistical analysis}

Categorical data were presented as frequencies with percentages and continuous data as means with standard deviations. Relations between categorical variables were assessed using the $\chi^{2}$ test. The two-sample $t$-test and Mann-Whitney $U$ test were used to compare independent variables. Multivariate regression analysis was performed to determine the main predictive factors. A receiver operating characteristic (ROC) curve was constructed for TMA length to test the various cut-off points in predicting hip fracture. The level of significance was set at $p \leq 0.05$.

\section{Results}

Table I demonstrates the mean and standard deviation (SD) values for age, BMI, and BMD values in both the fracture and control groups. There were no significant differences in age, $\mathrm{BMI}$, or BMD values between the groups ( $p>0.05)$.
Regarding geometric measurement parameters, the patients in group I had significantly lower MCT and LCT values (Table II). The mean FNW and $\mathrm{Q}$ angle were significantly higher in group I. Furthermore, TMA length was also found to be significantly greater in patients with hip fracture compared to controls, $85 \pm 14 \mathrm{~mm}$ and $66 \pm 12 \mathrm{~mm}$ respectively $(p<0.001)$. When the mean TMA lengths were compared between the groups with the age ( $\leq 65$ or $>65$ years) determined as the independent variable, the mean TMA length was also significantly greater in group I for both age groups ( $p<0.001$ ) (Figure 2). However, we did not detect any significant difference between the male and female gender $(p=0.6)$. Although the FNW, $Q$ angle, MCT, LCT, and TMA length were significantly correlated with hip fracture risk according to univariate analysis, multiple regression analysis demonstrated that the TMA length was the most significant variable in predicting the fracture risk ( $p<0.001 ; 95 \% \mathrm{Cl}: 0.852-0.912)$. The sensitivity of TMA length was $85 \%$ and the specificity was $75 \%$ with the cut-off value determined as $\geq 72 \mathrm{~mm}$ according to the ROC curve (Figure 3).

\section{Discussion}

The etiology and the mechanisms leading to hip fracture in the elderly have been reported as related to multiple factors [13]. Therefore, measuring femoral BMD alone may not accurately predict fracture risk, especially when measured BMD is not yet in the osteoporotic range [10]. Proximal femoral geometry has been investigated by several authors as an additional tool with

Table I. Demographic data of study population

\begin{tabular}{|c|c|c|c|}
\hline Parameter & $\begin{array}{c}\text { Group } 1 \\
\text { (mean } \pm \text { SD) }\end{array}$ & $\begin{array}{c}\text { Group } 2 \\
\text { (mean } \pm \text { SD) }\end{array}$ & $P$-value \\
\hline Age [years] & $78.3 \pm 9.2$ & $76.3 \pm 9.4$ & 0.118 \\
\hline $\mathrm{BMI}\left[\mathrm{kg} / \mathrm{m}^{2}\right]$ & $25.5 \pm 2.1$ & $25.4 \pm 3.5$ & 0.810 \\
\hline Femoral neck T score $\left[\mathrm{g} / \mathrm{cm}^{2}\right]$ & $0.68 \pm 0.11$ & $0.70 \pm 0.14$ & 0.185 \\
\hline Trochanteric T score $\left[\mathrm{g} / \mathrm{cm}^{2}\right]$ & $0.59 \pm 0.17$ & $0.61 \pm 0.10$ & 0.264 \\
\hline Total hip T-score $\left[\mathrm{g} / \mathrm{cm}^{2}\right]$ & $-1.7 \pm 1.1$ & $-1.64 \pm 0.99$ & 0.671 \\
\hline
\end{tabular}

Table II. Univariate analysis of the radiographic parameters tested as predictors of hip fracture

\begin{tabular}{|lccc|}
\hline Parameter & $\begin{array}{c}\text { Group 1 } \\
(\text { mean } \pm \text { SD })\end{array}$ & $\begin{array}{c}\text { Group 2 } \\
(\text { mean } \pm \text { SD })\end{array}$ & $P$-value \\
\hline Femoral neck width [mm] & $38.3 \pm 3.9$ & $35.5 \pm 4.2$ & $<0.001$ \\
\hline Q angle $\left[^{\circ}\right]$ & $132.1 \pm 6.5$ & $129.2 \pm 5.9$ & $<0.001$ \\
\hline Medial cortical thickness [mm] & $6.6 \pm 1.5$ & $9.1 \pm 1.6$ & $<0.001$ \\
\hline Lateral cortical thickness [mm] & $6.1 \pm 1.4$ & $7.6 \pm 1.4$ & $<0.001$ \\
\hline True moment arm [mm] & $85 \pm 1.4$ & $66 \pm 12$ & $<0.001$ \\
\hline
\end{tabular}




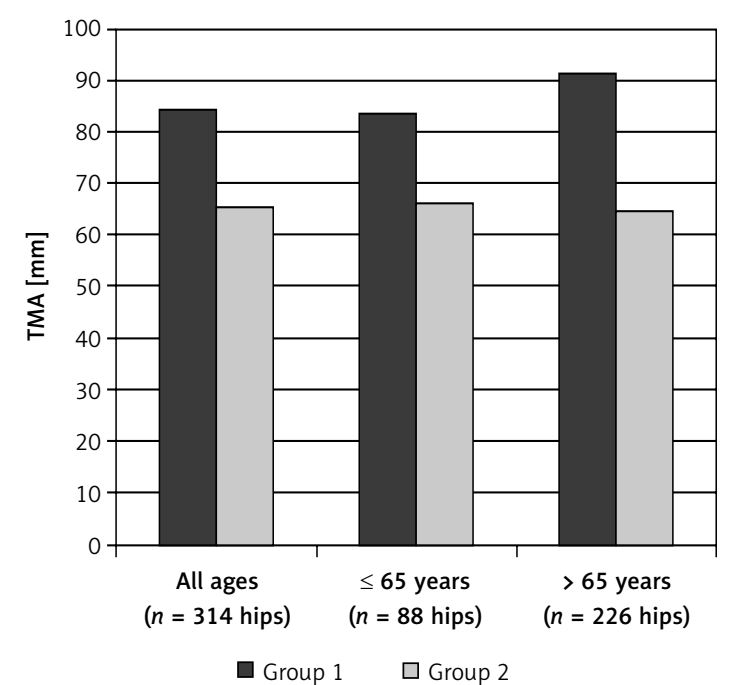

Figure 2. Comparison of mean TMA lengths among the age groups

BMD measurements for the establishment of the risk for a hip fracture in the elderly $[6-9,11]$. Various segments of the proximal femur contribute to the strength and resistance to the impact stress caused by a fall; thus several geometric measurements have been tested to develop a better understanding of the biomechanical properties increasing the fracture risk [7, 9-12]. According to Gregory et al., both the shape of the femur and the appearance of the trabecular architecture are associated with fracture risk [5]. Ulusoy et al. also reported that independently from BMD, geometric parameters significantly discriminated fractured patients [9]. The disproportional stress loading on the hip joint that originated due to a fall was demonstrated as positively correlated with a longer HAL as well as a longer FAL [14]. Femoral neck shaft angle ( $Q$ angle) is another geometric parameter which has widely been assessed by several investigators in the literature [7, 12, 15-17]. However, the results from different studies regarding the relationship between the increased risk of hip fracture with higher HAL, FAL, and $\mathrm{Q}$ angle values have been inconsistent and conflicting, mainly because these parameters may have great variations with respect to the height, weight, race, gender and age of the individual $[5,18]$. In the present study, there were no differences between the groups according to age, gender distribution, BMI, and BMD values. Femoral neck shaft angle ( $Q$ angle) was found to be significantly greater in the fracture group. Our findings were consistent with the literature.

Femoral neck width, MCT, and LCT are parameters which have also been evaluated as radiographic predictors of hip fracture in the elderly $[9,15,19$, 20]. Greater FNW has been found to be associated with an increased risk of hip fracture [10]. It was suggested that an increase in FNW may reflect

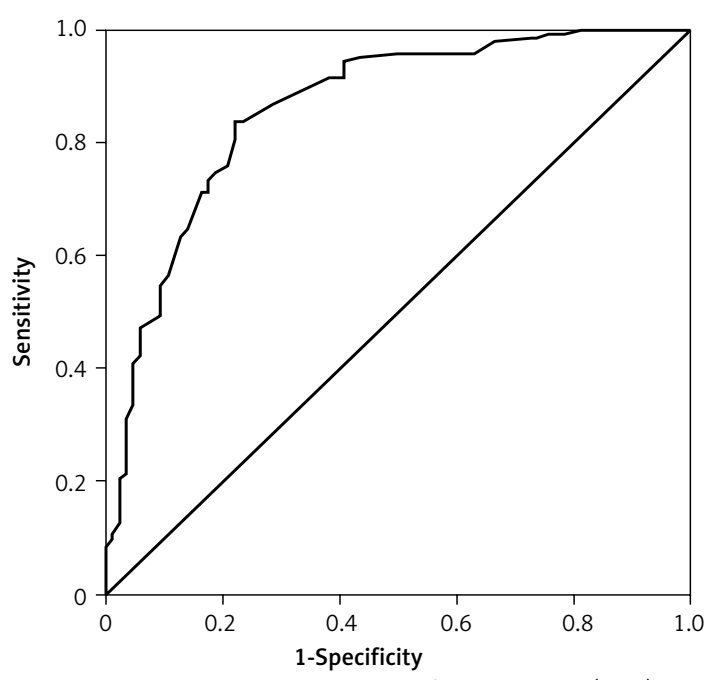

Figure 3. Receiver operating characteristic (ROC) curve for TMA to test the cut-off points in predicting hip fracture

adaptation to a gradual decrease in bone mass, with the possible mechanism for it being proposed as periosteal apposition [21]. On the other hand, Alonso et al. also hypothesized that greater FNW increased the moment of inertia to compensate for age-related bone loss, which may reduce the fracture risk [15]. Decreased MCT and LCT were also reported by different authors as significantly correlated with fracture risk $[19,20]$. Although several studies demonstrated an association between the changes in FNW, MCT, and LCT, many others have concluded that there was no significant relationship [10]. Therefore, there has been no consensus on the exact value of those geometric analyses. Ulusoy et al. emphasized that an MCT $\leq 8 \mathrm{~mm}$ and LCT $\leq 7 \mathrm{~mm}$ had $88 \%$ and $82 \%$ sensitivity to predict hip fracture risk, whereas their specificity was questionable [9]. According to the data that we acquired during the current study, FNW, MCT, and LCT were significantly different in the fracture group. The sensitivity of MCT $\leq 8 \mathrm{~mm}$ was $92 \%$, and it was $85 \%$ for LCT $\leq 7 \mathrm{~mm}$ in our study.

Although the overall evidence has suggested that assessing and measuring hip geometry can significantly improve the ability to identify people at risk for hip fracture, more research and product development has been emphasized as necessary to explore the application of radiographic markers in the clinical setting [10]. True moment arm, a relatively new geometric parameter described as a radiographic predictor, has been developed in order to achieve a stronger evaluation of the biomechanical load with respect to HAL, FAL, Q angle, and FNW [9]. The longer the TMA, the higher is the moment formed and the higher is the impact energy transmitted to the femoral neck. Ulusoy et al. concluded that TMA length of $\geq 75.11 \mathrm{~mm}$ had a sensitivity of $44.1 \%$ for predicting hip fracture [9]. In our study, TMA length was found to be sig- 
nificantly greater in patients with a hip fracture compared to controls. Furthermore, it was the most significant radiographic measurement in predicting the fracture risk according to multiple regression analysis. The sensitivity of TMA length was $85 \%$ and the specificity was $75 \%$, with the cut-off value determined as $\geq 72 \mathrm{~mm}$. The sensitivity and specificity of TMA length were found to be higher than the value mentioned by Ulusoy et al. [9]. However, their study included 34 fracture cases and 36 controls, whereas our study was conducted with 142 fracture cases with 172 intact hips of 86 healthy controls. With age ( $\leq 65$ or $>65$ years) as an independent variable, the difference was also significant for both age groups, while the sensitivity of TMA length did not show variations according to age groups.

We can note some limitations of the present study. First, it was not a prospectively designed study. Second, we did not apply a prior calculation for the sample sizes. However, post hoc analysis was performed, and the statistical power of our study in the aspect of making a comparison between the two groups according to FNW, Q angle, MCT, LCT, and TMA was 0.99 for each of the radiographic variables with an $\alpha$ value of 0.05 . Also, our patient groups had similar demographic features, which allowed us to obtain more comparable data.

In conclusion, predicting the risk of hip fracture in the elderly is crucial to establish preventive measures for reducing the incidence of hip fractures and, in turn, the burden on healthcare services. According to the data acquired during the present study, radiographic measurements including FNW, $\mathrm{Q}$ angle, MCT, LCT, and TMA length are simple, non-invasive, and effective tools for the prediction of fracture risk independently of BMD. Especially the TMA length may provide the most valuable radiographic information as a predictor for hip fracture in the elderly. Further prospective studies with larger cohorts are required to test the reproducibility of our findings.

\section{Conflict of interest}

The authors declare no conflict of interest.

\section{References}

1. Vergara I, Vrotsou K, Orive M, Gonzalez N, Garcia S, Quintana JM. Factors related to functional prognosis in elderly patients after accidental hip fractures: a prospective cohort study. BMC Geriatrics 2014; 14: 124.

2. Kannus P, Parkkari J, Sievänen $\mathrm{H}$, et al. Epidemiology of hip fractures. Bone 1996; 18: 57-63.

3. Cooper C, Campion G, Melton LJ. Hip fractures in the elderly: a world-wide projection. Osteoporos Int 1992; 2: 285-9.

4. Roche JJ, Wenn RT, Sahota O, Moran CG. Effect of comorbidities and postoperative complications on mortality after hip fracture in elderly people: prospective observational cohort study. BMJ 2005; 331: 1374.

5. Gregory JS, Stewart A, Undrill PE, Reid DM, Aspden RM. Bone shape, structure, and density as determinants of osteoporotic hip fracture: a pilot study investigating the combination of risk factors. Invest Radiol 2005; 40: 591-7.

6. Beck TJ, Looker AC, Ruff CB, Sievanen H, Wahner HW. Structural trends in the aging femoral neck and proximal shaft: analysis of the Third National Health and Nutrition Examination Survey dual-energy X-ray absorptiometry data. J Bone Miner Res 2000; 15: 2297-304.

7. Faulkner KG, Cummings SR, Black D, Palermo L, Glüer CC, Genant HK. Simple measurement of femoral geometry predicts hip fracture: the study of osteoporotic fractures. J Bone Miner Res 1993; 8: 1211-7.

8. Millard J, Augat P, Link TM, et al. Power spectral analysis of vertebral trabecular bone structure from radiographs: orientation dependence and correlation with bone mineral density and mechanical properties. Calcif Tissue Int 1998; 63: 482-9.

9. Ulusoy H, Bilgici A, Kuru O, Sarica N, Arslan S, Erkorkmaz $U$. A new value of proximal femur geometry to evaluate hip fracture risk: true moment arm. Hip Int 2008; 18: 101-7.

10. Brownbill RA, llich JZ. Hip geometry and its role in fracture: what do we know so far? Curr Osteoporos Rep 2003; 1: 25-31.

11. Dincel VE, Sengelen M, Sepici V, Cavusoglu T, Sepici B. The association of proximal femur geometry with hip fracture risk. Clin Anat 2008; 21: 575-80.

12. Bergot C, Bousson V, Meunier A, Laval-Jeantet M, Laredo JD. Hip fracture risk and proximal femur geometry from DXA scans. Osteoporos Int 2002; 13: 542-50.

13. Bass M, Ford MA, Brown B, Mauromoustakos A, Keathley RS. Variables for the prediction of femoral bone mineral status in American women. South Med J 2006; 99: 115-23.

14. Yang RS, Wang SS, Liu TK. Proximal femoral dimension in elderly Chinese women with hip fractures in Taiwan. Osteoporos Int 1999; 10: 109-13.

15. Alonso CG, Curiel MD, Carranza FH, Cano RP, Perez AD. Femoral bone mineral density, neck-shaft angle and mean femoral neck width as predictors of hip fractures in men and women. Multicenter Project for Research in Osteoporosis. Osteoporos Int 2002; 11: 714-20.

16. Partanen J, Jamsa T, Jalovaara P. Influence of the upper femur and pelvic geometry on the risk and type of hip fractures. J Bone Miner Res 2001; 16: 1540-6.

17. Gnudi S, Ripamonti C, Lisa L, Fini M, Giardino R, Giavaresi G. Proximal femur geometry to detect and distinguish femoral neck fractures from trochanteric fractures in postmenopausal women. Osteoporos Int 2002; 13: 69-73.

18. Looker AC, Beck TJ, Orwoll ES. Does body size account for gender differences in femur bone density and geometry? J Bone Miner Res 2001; 16: 1291-9.

19. El-Kaissi S, Pasco JA, Henry MJ, et al. Femoral neck geometry and hip fracture risk: the Geelong osteoporosis study. Osteoporos Int 2005; 16: 1299-303.

20. Szulc P, Douboeuf F, Schott AM, Dargent-Molina P, Meunier PJ, Delmas PD. Structural determinants of hip fracture in elderly women: reanalysis of the data from the EPIDOS study. Osteoporos Int 2006; 17: 231-6.

21. Cheng X, Li J, Lu Y, Keyak J, Lang T. Proximal femoral density and geometry measurements by quantitative computed tomography: association with hip fracture. Bone 2007; 40: 169-74. 